\title{
Rhodium catalyzed hydroformylation of monoterpenes containing a sterically encumbered trisubstituted endocyclic double bond under mild conditions
}

\author{
José G. da Silva ${ }^{\mathrm{a}}$, Humberto J.V. Barros ${ }^{\mathrm{a}}$, Angelica Balanta ${ }^{\mathrm{b}}$, Alberto Bolaños ${ }^{\mathrm{b}}$, \\ Maria L. Novoa ${ }^{c}$, Marisela Reyes ${ }^{c}$, Ricardo Contreras ${ }^{c}$, J. Carles Bayón ${ }^{\mathrm{d}}$, \\ Elena V. Gusevskaya ${ }^{\mathrm{a}, *}$, Eduardo N. dos Santos ${ }^{\mathrm{a}, *}$ \\ ${ }^{a}$ Departamento de Química, ICEX, Universidade Federal de Minas Gerais, 31270-901 Belo Horizonte, MG, Brazil \\ ${ }^{\mathrm{b}}$ Departamento de Química, Universidad del Valle, Cali, Colombia \\ ${ }^{\mathrm{c}}$ Departamento de Química, Universidad de Los Andes, Mérida, Venezuela \\ ${ }^{\mathrm{d}}$ Departament de Química, Universitat Autonòma de Barcelona, Spain
}

Received 20 December 2006; received in revised form 10 April 2007; accepted 12 April 2007

Available online 20 April 2007

\begin{abstract}
The rhodium catalyzed hydroformylation of endocyclic monoterpenes, that is, 2-carene (1), 3-carene (2), and $\alpha$-pinene (3), in the presence of $\mathrm{PPh}_{3}$ or various diphosphines and phosphites has been studied. The unmodified Rh catalyst promotes an intense isomerization of both carenes whose hydroformylation occurs rather slowly, and results in a complex mixture of aldehydes and alcohols. The addition of $\mathrm{PPh}_{3}$, diphosphines or $\mathrm{P}(\mathrm{OPh})_{3}$ in a $\mathrm{P} / \mathrm{Rh}$ ratio as high as 20 , efficiently prevents the isomerization, but the activity for hydroformylation is drastically reduced. On the other hand, the use of a bulky $\mathrm{P}\left(\mathrm{O}-o_{-}{ }^{\mathrm{t}} \mathrm{BuPh}\right)_{3}$ ligand both reduces the isomerization, and significantly increases the hydroformylation rate. All three sterically crowded olefins $\mathbf{1 - 3}$ have been efficiently hydroformylated under relatively mild reaction conditions $\left(80-100{ }^{\circ} \mathrm{C}\right.$, 40-80 atm) to a main aldehyde (2-formylcarane, 4-formylcarane, and 3-formylpinene, respectively) with good chemo- and regioselectivity, and almost $100 \%$ stereoselectivity for the trans isomers.
\end{abstract}

(C) 2007 Elsevier B.V. All rights reserved.

Keywords: 2-Carene; 3-Carene; $\alpha$-Pinene; Hydroformylation; Rhodium catalyst; Bulky phosphite

\section{Introduction}

The catalytic functionalization of monoterpenes is an important route to add value to these renewable raw materials easily available from biomass. A number of their functionalized derivatives have olfactory and biological activity, and can be interesting for the pharmaceutical and fragrance industries. [1-3] The rhodium catalyzed hydroformylation of special olefins represents a versatile and one of the least expensive synthetic pathways to aldehydes in the fine chemicals industry. In recent years, we have been systematically studying the hydroformylation of various monoterpenes, such as myrcene,

\footnotetext{
* Corresponding authors. Tel.: +55 313 4995743; fax: +55 3134995700 .

E-mail addresses: elena@ufmg.br (E.V. Gusevskaya), nicolau@ufmg.br (E.N. dos Santos).
}

limonene, $\beta$-pinene, and camphene [4-10]. All these substrates contain exocyclic terminal double bonds, which can be relatively easily hydroformylated. On the other hand, endocyclic monoterpenes, that is, 2-carene (1), 3-carene (2), and $\alpha$-pinene (3), are much more reluctant to undergo hydroformylation, and it is not surprising that the available information about their hydroformylation is scarce [11-16]. However, these reactions are very attractive because they could lead directly to aldehydes 4-6, useful as fragrances (Scheme 1) [1]. It is also interesting that, as these monoterpenes possess a rigid bicyclic core, they could afford corresponding aldehydes with high levels of diastereoselectivity.

Considering that olefins 1-3 have endocyclic trisubstituted double bonds, it is reasonable to expect that their hydroformylation might be troublesome. Indeed, the rhodium catalyzed hydroformylation of $\mathbf{2}$ and $\mathbf{3}$ has been efficiently achieved only under pressures as high as $600 \mathrm{~atm}$ at $110-120^{\circ} \mathrm{C}[11,12]$. The 


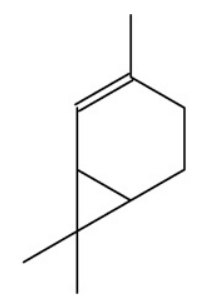

1

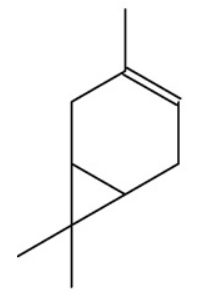

2

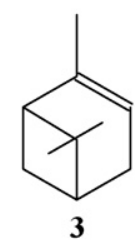

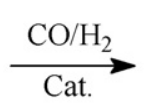

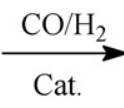

Scheme 1

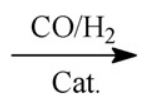

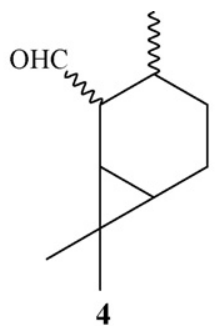

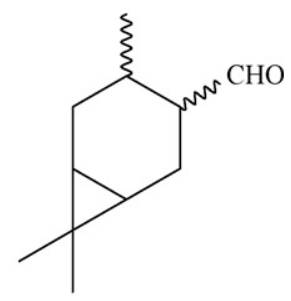

5

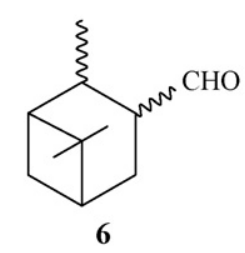

$\left.10^{-1} \mathrm{mmol}\right)$, substrate $(2.5 \mathrm{mmol})$, dodecane (internal standard, $1.2 \mathrm{mmol})$, and benzene $(5.0 \mathrm{~mL})$ was transferred from a Schlenck tube under argon into a stainless steel magnetically stirred $20 \mathrm{~mL}$ reactor. The reactor was pressurized to 40 $80 \mathrm{~atm}$ total pressure $\left(\mathrm{CO} / \mathrm{H}_{2}=2 / 1-1 / 2\right)$, and placed in an oil bath preheated at the desired temperature. After carrying out the reaction and cooling to room temperature, the excess $\mathrm{CO}$ and $\mathrm{H}_{2}$ was slowly vented.

The products were quantitatively analyzed by gas chromatography (GC) using a Shimadzu 17B instrument fitted with a Carbowax 20M capillary column and a flame ionization detector. Conversion and selectivity were determined by GC.

The products were separated by column chromatography (silica) using mixtures of hexane and $\mathrm{CH}_{2} \mathrm{Cl}_{2}$ as eluents, and identified by GC/MS (Hewlett-Packard MSD 5890/Series II instrument operating at $70 \mathrm{eV}),{ }^{1} \mathrm{H}$ and ${ }^{13} \mathrm{C}$-NMR spectroscopy (Bruker CXP-400, tetramethylsilane, $\mathrm{CDCl}_{3}$, COSY, HMQC, and DEPT experiments). The stereochemistry of the products was elucidated by NOESY experiments. In Figs. 1 and 2, the structures of only one of the enantiomers for each diastereoisomer are presented. The usual numbering for carane and pinane derivatives has been used.

3,7,7-Trimethylbicyclo(4.1.0)-heptane-2-carbaldehyde (trans, shorter CG retention time) (4a) (light yellow oil): MS $(\mathrm{m} / \mathrm{z} /$ rel.int. $): \quad 166 / 4 \quad\left(\mathrm{M}^{+}\right) ; \quad 151 / 23 \quad\left(\mathrm{M}^{+}-\mathrm{CH}_{3}\right) ; 137 / 93$ $\left(\mathrm{M}^{+}-\mathrm{CHO}\right) ; 109 / 23 ; 95 / 52 ; 93 / 19 ; 81 / 100 ; 79 / 22 ; 77 / 17 ; 69 /$ $27 ; 67 / 62 ; 55 / 19$. For NMR data see Fig. 1.

3,7,7-Trimethylbicyclo(4.1.0)-heptane-2-carbaldehyde (cis, longer CG retention time) (4b) (light yellow oil): MS $(\mathrm{m} / \mathrm{z} /$ rel.int.): 166/2 $\left(\mathrm{M}^{+}\right) ; 151 / 11\left(\mathrm{M}^{+}-\mathrm{CH}_{3}\right) ; 137 / 43\left(\mathrm{M}^{+}-\mathrm{CHO}\right)$; 135/30; 124/15; 97/15; 96/19; 95/49; 93/18; 83/26; 81/100; 79/ $22 ; 71 / 34 ; 69 / 83 ; 67 / 64 ; 57 / 25 ; 55 / 49$. For NMR data see Fig. 1.

3,7,7-Trimethylbicyclo(4.1.0)-heptane-4-carbaldehyde (trans) (5a) (light yellow oil): MS ( $\mathrm{m} / \mathrm{z} / \mathrm{rel}$.int.): 166/8 $\left(\mathrm{M}^{+}\right)$; $151 / 20\left(\mathrm{M}^{+}-\mathrm{CH}_{3}\right) ; 137 / 30\left(\mathrm{M}^{+}-\mathrm{CHO}\right) ; 135 / 64 ; 123 / 48 ; 109 /$ 19; 107/17; 105/20; 96/22; 95/56; 93/74; 91/30; 82/19; 81/100; $79 / 40 ; 77 / 26 ; 71 / 39 ; 69 / 36 ; 67 / 82 ; 55 / 49$. For NMR data see Fig. 2.

3-Formylpinane (trans) (6a) (light yellow oil). Compound described by Siegel and Himmele [11] and Sirol and Kalck [16]. For complete NMR data see Fig. 2.

10-Formylcarane (8) (two GC peaks with identical fragmentation pattern): $\mathrm{MS}\left(\mathrm{m} / \mathrm{z} / \mathrm{rel}\right.$.int.): $166 / 2\left(\mathrm{M}^{+}\right) ; 151 / 6$ $\left(\mathrm{M}^{+}-\mathrm{CH}_{3}\right) ; 122 / 82\left(\mathrm{M}^{+}-\mathrm{CH}_{2} \mathrm{CHO}-\mathrm{H}\right) ; 107 / 73 ; 81 / 29 ; 79 /$ $100 ; 68 / 38 ; 55 / 29 ; 41 / 59$.

10-Formylpinane (10a) (trans) and (10b) (cis, longer GC retention time). Compounds described by Azzaroni et al. [19] and Sirol and Kalck [16].

\section{Results and discussion}

We have studied the hydroformylation of 2-carene (1), 3carene (2), and $\alpha$-pinene (3) using $[\mathrm{Rh}(\operatorname{cod})(\mathrm{OMe})]_{2}$ as a catalyst precursor in the presence of triphenylphosphine or various diphosphines and phosphites as P-donor auxiliary ligands. Under all conditions used, the reactions with each

substrate resulted in two major carbonylated products ( $\mathbf{4}$ and $\mathbf{5}$
In a typical run, a solution containing $[\mathrm{Rh}(\operatorname{cod})(\mathrm{OMe})]_{2}$ $\left(3.1 \times 10^{-3} \mathrm{mmol}\right)$, phosphorous ligand $\left(6.0 \times 10^{-2}\right.$ to $1.8 \times$ 

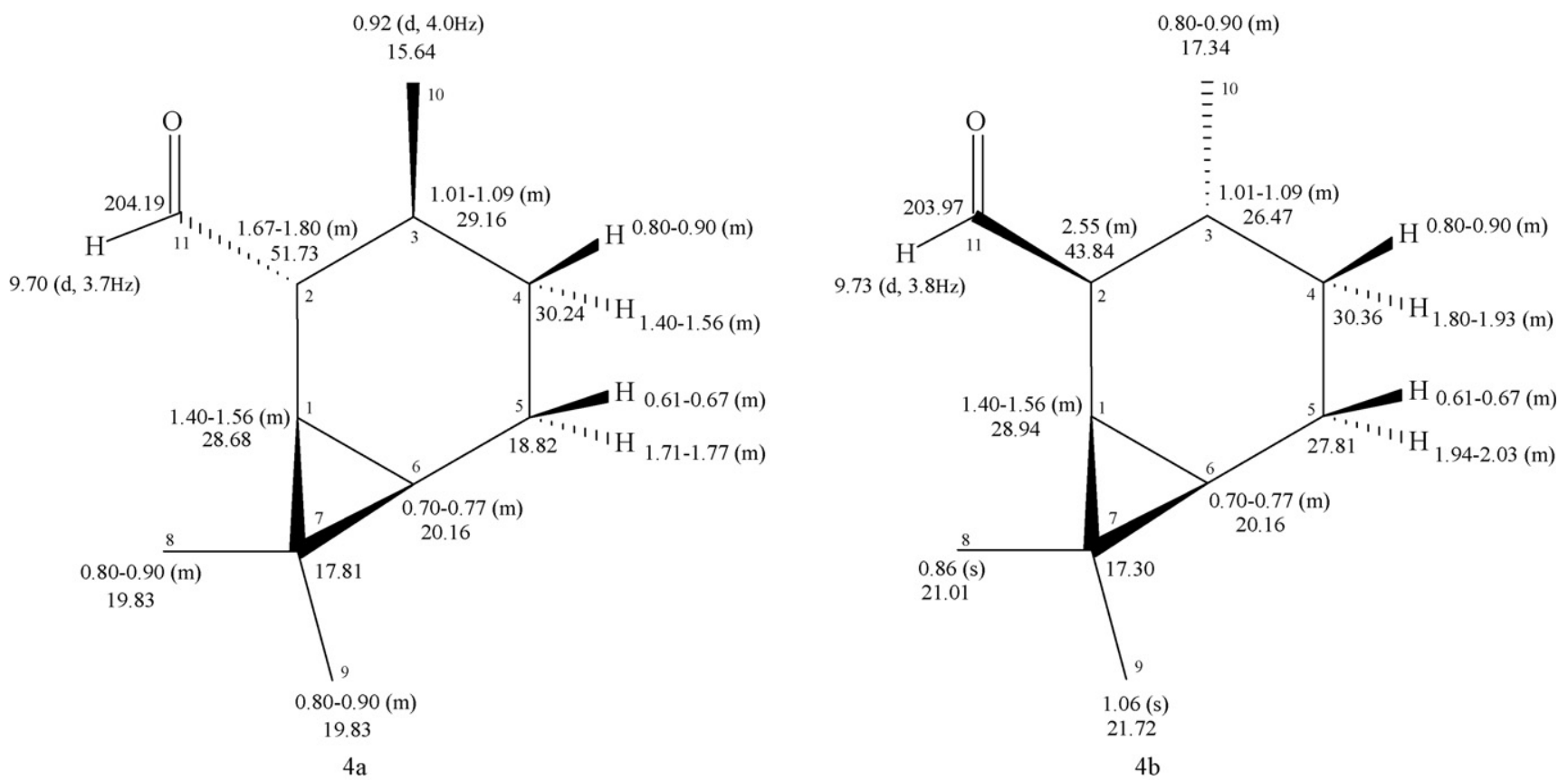

Fig. 1. NMR chemical shifts for compounds $\mathbf{4 a}$ and $\mathbf{4 b}$.

from $\mathbf{1}$ and 2, $\mathbf{6}$ and $\mathbf{1 0}$ from 3) formed in 85-94\% combined selectivity in most of the runs with P-modified catalysts (Schemes 2 and 3). The GC mass balance was based on the substrate charged using dodecane as an internal standard. The difference, which was very small for most of the runs, was attributed to the formation of high molecular weight products, which could not be determined by GC. The products given as "others" in the tables are mainly other isomers of the substrates, unidentified aldehydes, and alcohols formed due to the hydrogenation of primarily formed aldehydes. Hydrogenated substrates were formed in very small amounts, and were also included in "others".

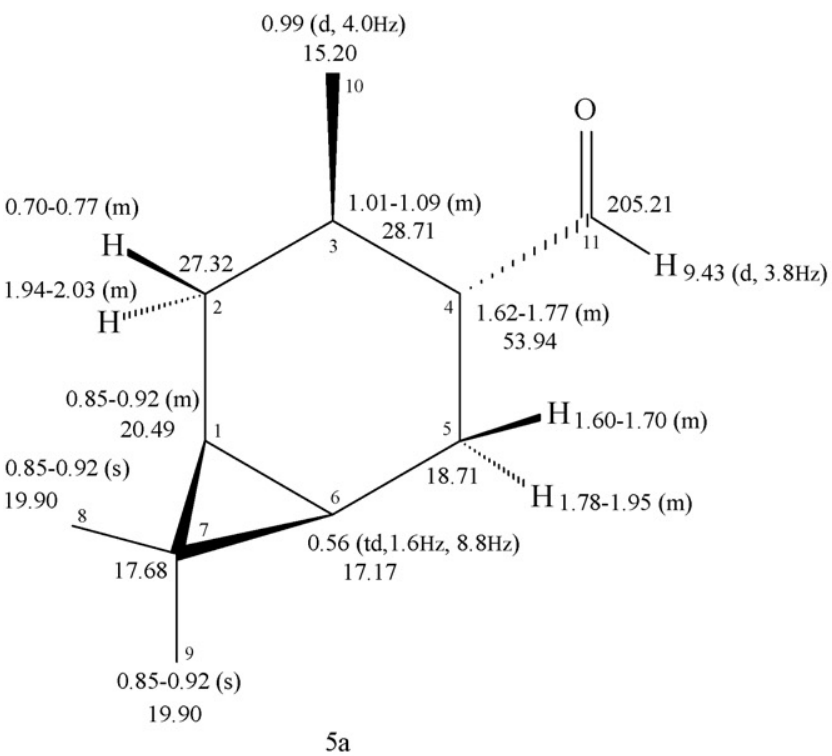

\subsection{Hydroformylation of 2-carene and 3-carene}

The data on the hydroformylation of carenes $\mathbf{1}$ and $\mathbf{2}$ are presented in Tables 1-3. In the absence of the P(III) ancillary ligand, the $\mathrm{RhH}(\mathrm{CO})_{4}$ catalyst promotes the extensive isomerization of both substrates into each other, and also into the isomer 7 containing an exocyclic terminal double bond (Scheme 2) (Table 1, entries 1, 2, 6, and 7). Although the latter isomer was not identified, its formation can be inferred from the structure of the identified aldehyde 8 . At $80^{\circ} \mathrm{C}$ (Table 1, entries 1 and 6), the hydroformylation of both carenes occurred rather slowly and the solutions after $24-\mathrm{h}$ reactions still contained

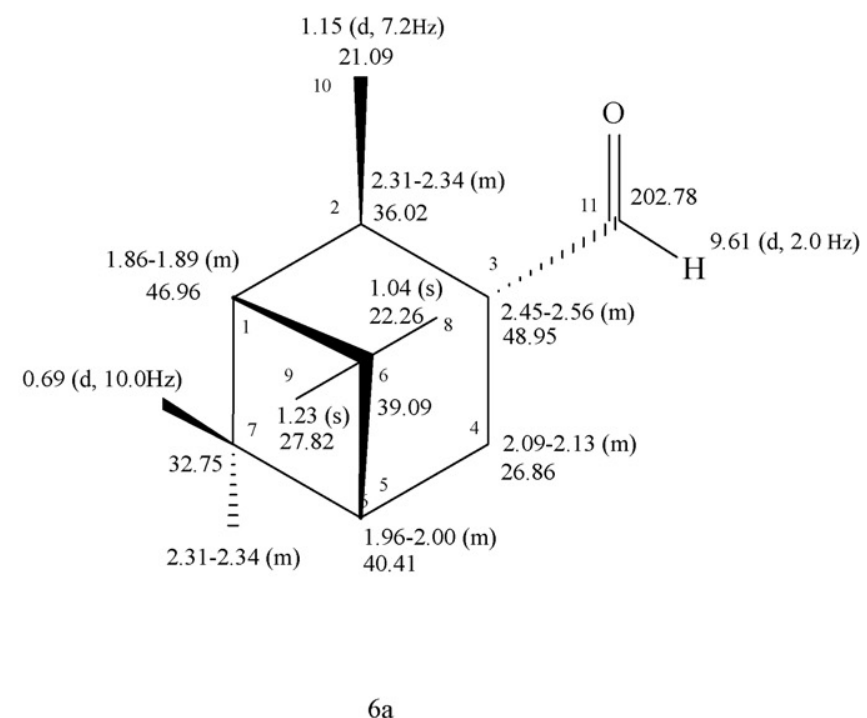

Fig. 2. NMR chemical shifts for compounds 5a and $6 \mathbf{a}$. 


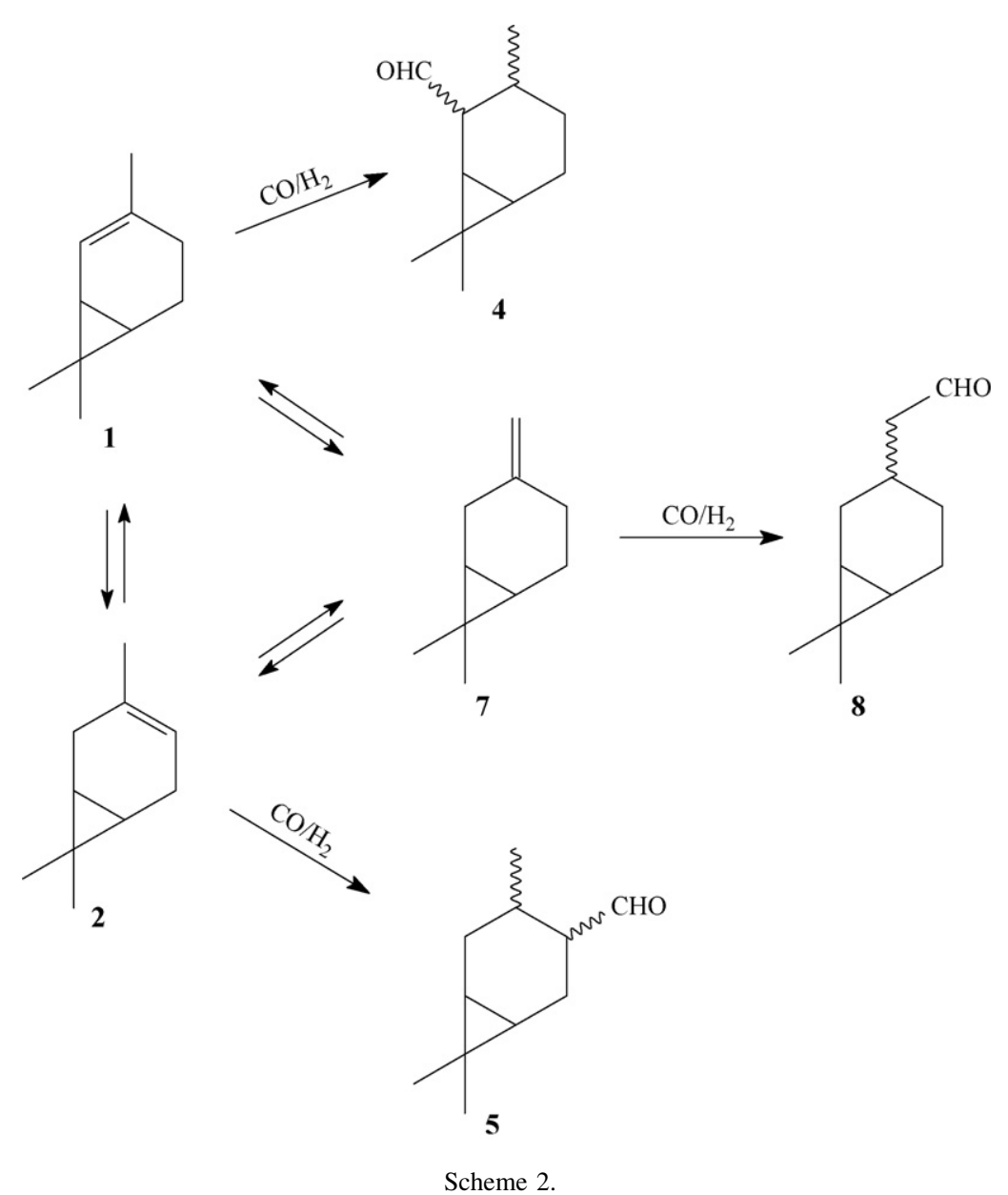

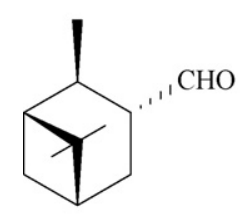

$6 \mathbf{a}$

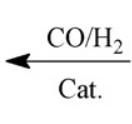

Cat.

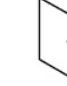

3

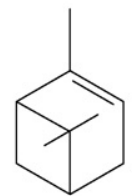

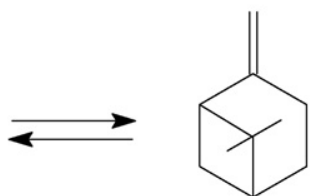

9

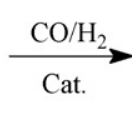

Scheme 3. significant amounts of carenes. It is noteworthy that the reaction proceeded with high regioselectivity, as no products containing the formyl group in $\mathrm{C}-1$ were detected. At $100{ }^{\circ} \mathrm{C}$ (Table 1 , entries 2 and 7), the conversion of the substrates was faster, however, along with three major aldehydes $\mathbf{4}, \mathbf{5}$, and $\mathbf{8}$, a number of minor unidentified GC peaks with the retention times similar to the ones of $\mathbf{4 , 5}$, or $\mathbf{8}$ were detected in significant amounts. A preliminary ${ }^{13} \mathrm{C}$ NMR analysis of the product mixture suggested the presence of other aldehydes and alcohols.

The isomer 7 has a disubstituted terminal double bond, and is expected to be more reactive in hydroformylation than $\mathbf{1}$ and 2. Therefore, even if present in a low concentration, carene 7 may give appreciable amounts of aldehyde $\mathbf{8}$ because its consumption shifts the isomerization equilibrium from $\mathbf{1}$ (or $\mathbf{2}$ ) towards 7 (Scheme 2).
Product $\mathbf{8}$ can have a pair of diastereoisomers due to the relative position of the aldehyde group and the isopropylidene bridge. Indeed, the GC-MS analysis show a pair of distinguishable GC peaks of comparable intensities and identical MS fragmentation pattern, which present a fragment at $m / z=122$ with a relative intensity of $82 \%$ corresponding to the loss of a $\mathrm{CH}_{2} \mathrm{CHO}$ and one hydrogen atom from 8 . On the other hand, products $\mathbf{4}$ and $\mathbf{5}$ can have four enantiomeric pairs of diastereoisomers (or four diastereoisomers when originated from the enantiomerically pure substrate) resulting from the different possibilities for the relative positions of the methyl, formyl, and isopropylidene groups. Nevertheless, due to the hydroformylation mechanism requirements, the addition of the hydrogen, and the formyl group is syncoplanar, which implies that the formyl and methyl groups in $\mathbf{4}$ and $\mathbf{5}$ derived from $\mathbf{1}$ and $\mathbf{2}$, respectively, will always be trans to each other. This reduces 
Table 1

Rhodium catalyzed hydroformylation of 2-carene (1) and 3-carene (2): effect of phosphorous ligand ${ }^{\mathrm{a}}$

\begin{tabular}{|c|c|c|c|c|c|c|c|c|}
\hline \multirow[t]{2}{*}{ Entry } & \multirow[t]{2}{*}{ Substrate } & \multirow[t]{2}{*}{ Ligand } & \multirow[t]{2}{*}{ Conversion $(\%)$} & \multicolumn{5}{|c|}{ Product distribution (\%) } \\
\hline & & & & Isomer $^{\mathrm{b}}$ & 4 & 5 & 8 & Others \\
\hline $1^{\mathrm{c}}$ & 1 & - & 42 & 58 & 23 & 5 & 2 & 12 \\
\hline 3 & 1 & $\mathrm{PPh}_{3}$ & 15 & 8 & 78 & - & 3 & 11 \\
\hline 4 & 1 & $\mathrm{P}\left(\mathrm{O}-o{ }^{\mathrm{t}} \mathrm{BuPh}\right)_{3}$ & 98 & 3 & 75 & 16 & - & 6 \\
\hline $5^{\mathrm{c}}$ & 1 & $\mathrm{P}\left(\mathrm{O}-o^{-}{ }^{\mathrm{t}} \mathrm{BuPh}\right)_{3}$ & 77 & 8 & 86 & 2 & - & 4 \\
\hline 8 & 2 & $\mathrm{PPh}_{3}$ & 7 & 5 & - & 38 & 2 & 55 \\
\hline 9 & 2 & $\mathrm{P}\left(\mathrm{O}-o-{ }^{\mathrm{t}} \mathrm{BuPh}\right)_{3}$ & 89 & 6 & 34 & 49 & - & 11 \\
\hline $10^{\mathrm{c}}$ & 2 & $\mathrm{P}\left(\mathrm{O}-\sigma^{-}{ }^{\mathrm{t}} \mathrm{BuPh}\right)_{3}$ & 49 & 10 & 23 & 55 & - & 12 \\
\hline $11^{\mathrm{d}}$ & 2 & $\mathrm{P}\left(\mathrm{O}-o^{-}{ }^{\mathrm{t}} \mathrm{BuPh}\right)_{3}$ & 13 & 12 & 8 & 40 & - & 40 \\
\hline
\end{tabular}

${ }^{\mathrm{a}}$ Reaction conditions: substrate: $2.5 \mathrm{mmol}$; $[\mathrm{Rh}(\operatorname{cod})(\mathrm{OMe})]_{2}: 3.1 \times 10^{-3} \mathrm{mmol}$; ligand (if any): $1.2 \times 10^{-1} \mathrm{mmol}$; benzene: $5 \mathrm{~mL}, 80 \mathrm{~atm}\left(\mathrm{CO} / \mathrm{H}_{2}=1\right)$; $100{ }^{\circ} \mathrm{C}$, $24 \mathrm{~h}$.

b 2 in runs with 1 and $\mathbf{1}$ in runs with 2.

c $80{ }^{\circ} \mathrm{C}$.

${ }^{\mathrm{d}} \mathrm{PPh}_{3}\left(3.1 \times 10^{-2} \mathrm{mmol}\right)$ was added.

Table 2

Rhodium catalyzed hydroformylation 2-carene (1) and 3-carene (2) promoted by $\mathrm{P}\left(\mathrm{O}-\mathrm{o}^{\mathrm{t}}{ }^{\mathrm{BuPh}}\right)_{3}$ : Effect of phosphorous to rhodium ratio $([\mathrm{P}] /[\mathrm{Rh}])^{\mathrm{a}}$

\begin{tabular}{|c|c|c|c|c|c|c|c|c|}
\hline \multirow[t]{2}{*}{ Entry } & \multirow[t]{2}{*}{ Substrate } & \multirow[t]{2}{*}[\mathrm{P}]{$/[\mathrm{Rh}]$} & \multirow[t]{2}{*}{ Conversion (\%) } & \multicolumn{5}{|c|}{ Product distribution (\%) } \\
\hline & & & & Isomer $^{\mathrm{b}}$ & 4 & 5 & 8 & Others \\
\hline 2 & 1 & - & 81 & 22 & 19 & 15 & 8 & 36 \\
\hline 12 & 1 & 10 & 92 & 8 & 69 & 17 & 2 & 4 \\
\hline 4 & 1 & 20 & 98 & 3 & 75 & 16 & - & 6 \\
\hline 13 & 1 & 30 & 95 & 6 & 75 & 13 & 2 & 4 \\
\hline 7 & 2 & - & 67 & 38 & 11 & 20 & 5 & 26 \\
\hline 14 & 2 & 10 & 94 & 3 & 28 & 48 & 2 & 19 \\
\hline 9 & 2 & 20 & 89 & 6 & 34 & 49 & - & 11 \\
\hline 15 & 2 & 30 & 90 & 5 & 35 & 47 & 3 & 10 \\
\hline
\end{tabular}

${ }^{a}$ Reaction conditions: substrate: $2.5 \mathrm{mmol} ;[\mathrm{Rh}(\operatorname{cod})(\mathrm{OMe})]_{2}: 3.1 \times 10^{-3} \mathrm{mmol}$; benzene: $5 \mathrm{~mL}, 80 \mathrm{~atm}\left(\mathrm{CO} / \mathrm{H}_{2}=1\right) ; 100{ }^{\circ} \mathrm{C}, 24 \mathrm{~h}$.

b 3-Carene in runs with $\mathbf{1}$ and 2-carene in runs with 2.

the possibilities to two enantiomeric pairs or two diastereoisomers. Indeed, only one pair of GC distinguishable peaks is observed for both $\mathbf{4}$ and $\mathbf{5}$.

In an attempt to control the isomerization, $\mathrm{PPh}_{3}$ was added to the reaction solutions (Table 1, entries 3 and 8). The isomerization decreased drastically but the substrate conversion also decreased proportionately, and only a $15 \%$ conversion of 2-carene occurred in $24 \mathrm{~h}$ at $100{ }^{\circ} \mathrm{C}$. However, the product of its hydroformylation, aldehyde $\mathbf{4}$, was obtained in high selectivity (78\%), with no aldehyde $\mathbf{5}$, and only small amounts of aldehyde 8 being detected (Table 1, entry 3). It is noteworthy that aldehyde $\mathbf{4}$ is formed almost exclusively as a single diasteroisomer having a formyl group and cyclopropane ring in a trans position (trans isomer 4a) (see Section 3.2).

At a $\mathrm{P} / \mathrm{Rh}$ atomic ratio of 20 used in entries 3 and 8 , it is expected that most of the rhodium centers coordinate more than one phosphorous ligand. In a previous work, we demonstrated that rhodium species containing more than one P-ligand (e.g. systems promoted by chelating phosphines) exhibited low activity in the hydroformylation of terpenes with exocyclic disubstituted double bonds, such as $\beta$-pinene and camphene

Table 3

Rhodium catalyzed hydroformylation of 2-carene (1): Effect of partial pressures of $\mathrm{CO}$ and $\mathrm{H}_{2}{ }^{\mathrm{a}}$

\begin{tabular}{|c|c|c|c|c|c|c|c|}
\hline \multirow[t]{2}{*}{ Entry } & \multicolumn{2}{|c|}{ Pressure (atm) } & \multirow[t]{2}{*}{ Conversion $(\%)$} & \multicolumn{4}{|c|}{ Product distribution (\%) } \\
\hline & $\mathrm{CO}$ & $\mathrm{H}_{2}$ & & 3-Carene & $4 \mathbf{a}$ & $5 \mathbf{a}$ & Others \\
\hline 5 & 40 & 40 & 77 & 8 & 86 & 2 & 4 \\
\hline 17 & 20 & 40 & 90 & 9 & 81 & 6 & 4 \\
\hline 18 & 40 & 20 & 73 & 10 & 86 & 2 & 2 \\
\hline
\end{tabular}

${ }^{\mathrm{a}}$ Reaction conditions: substrate: $2.5 \mathrm{mmol} ;[\mathrm{Rh}(\operatorname{cod})(\mathrm{OMe})]_{2}: 3.1 \times 10^{-3} \mathrm{mmol} ; \mathrm{P}\left(\mathrm{O}-\mathrm{o}^{\mathrm{t}}{ }^{\mathrm{B}} \mathrm{BuPh}\right)_{3}: 1.2 \times 10^{-1} \mathrm{mmol} ;$ benzene: $5 \mathrm{~mL}, 80{ }^{\circ} \mathrm{C}, 24 \mathrm{~h}$. 
[4]. It seems that for both carenes this is even more critic, as the conversions are very low in these runs.

At lower $\mathrm{P} / \mathrm{Rh}$ ratios using $\mathrm{PPh}_{3}$, the conversions are higher but the process is greatly complicated by the substrate isomerization. When $\mathrm{PPh}_{3}$ was substituted by 1,3-bis(diphenylphosphino)propane or 1,4-bis(diphenylphosphino)butane under the conditions of entries 3 and 8 , the conversion of both 1 and 2 dropped to virtually zero. A similar effect was observed for the system with triphenylphosphite, $\mathrm{P}(\mathrm{OPh})_{3}$, which binds the metal center more strongly than $\mathrm{PPh}_{3}$, less than $5 \%$ conversion was observed after $24 \mathrm{~h}$ under the conditions of entries 3 and 8 . Once again, the reason seems to be that most of the rhodium centers are bound to more than one phosphite molecule which hinders the coordination of sterically encumbered substrates.

Thus, although the addition of phosphorous ligands mentioned above does prevent the isomerization of the substrates, their excess favors the formation of bis(ligand), and probably, tris(ligand) rhodium species, which are completely inactive in the hydroformylation of both carenes. On the other hand, employing the bulky $\mathrm{P}\left(\mathrm{O}-\mathrm{o}^{\mathrm{t}}{ }^{\mathrm{BuPh}}\right)_{3}$ allowed reduction of the isomerization, and also significantly increased the rate of the hydroformylation at $100{ }^{\circ} \mathrm{C}$ (entries 4 and 9). Even at $80{ }^{\circ} \mathrm{C}$, the reaction occurs at significant rates for both carenes, and selectivities for $\mathbf{4}$ and $\mathbf{5}$ are even better (entries 5 and 10). The $\mathrm{Rh} / \mathrm{P}\left(\mathrm{O}-o^{\mathrm{t}}{ }^{\mathrm{t}} \mathrm{BuPh}\right)_{3}$ system was successfully used for the first time by van Leeuwen and Roobeek for the hydrofomylation of otherwise unreactive olefins [18]. Since then, it has been used in the hydroformylation of a large number of alkenes. In the context of the present work, the successful hydroformylation of steroids containing an endocyclic trisubstituted double bound, similar to that of substrates $\mathbf{1}-\mathbf{3}$, should be mentioned [20]. Due to the large cone angle of $\mathrm{P}\left(\mathrm{O}-\mathrm{o}^{\mathrm{t}} \mathrm{BuPh}\right)_{3}\left(175^{\circ}\right)$, even at phosphorous to rhodium atomic ratios as high as 50 , catalytic species containing only one ligand per rhodium center largely predominate. In these species, the catalytic center has sufficient room to allow the coordination of the substrate. Furthermore, the weakly electrondonating ( $\chi$-value of 30.50 versus 13.25 for $\mathrm{PPh}_{3}$ ), and strongly electron-withdrawing properties of $\mathrm{P}\left(\mathrm{O}-\mathrm{o}^{\mathrm{t}}{ }^{\mathrm{BuPh}}\right)_{3}$ favors more facile $\mathrm{CO}$ dissociation and stronger olefin association with rhodium. [21].

The hydroformylation of 2-carene with the $\mathrm{Rh} / \mathrm{P}(\mathrm{O}-$ $o$ - $\left.{ }^{\mathrm{t}} \mathrm{BuPh}\right)_{3}$ system mainly results in the corresponding aldehyde 4 (selectivity of $75 \%$ at $100{ }^{\circ} \mathrm{C}$, Table 1 , entry 4 ). The major side product $(16 \%)$ is aldehyde 5 derived from 3-carene, whereas the amounts of other side products are considerably reduced compared with nonpromoted systems. At $80{ }^{\circ} \mathrm{C}$, the selectivity for 4 improves significantly up to $86 \%$ (Table 1, entry 5). On the other hand, the selectivity of the hydroformylation of 3-carene is more difficult to control. Even with $\mathrm{P}\left(\mathrm{O}-\boldsymbol{o}^{\mathrm{t}}{ }^{\mathrm{B}} \mathrm{BuPh}\right)_{3}$ as a promoter (entry 9), large amounts of aldehyde 4, derived from 2-carene, are formed and selectivity for aldehyde 5 does not exceed $49 \%$. At lower temperature $\left(80{ }^{\circ} \mathrm{C}\right.$, entry 10$)$, selectivity is slightly better $(55 \%)$ but aldehyde $\mathbf{4}$ is still formed in significant amounts. It is important, nevertheless, that a total selectivity for both aldehydes is rather high (ca. $80 \%$ ).
It has been suggested that a mixed ligand system containing $\mathrm{P}\left(\mathrm{O}-\mathrm{o}-{ }^{\mathrm{t}} \mathrm{BuPh}\right)_{3}$ and $\mathrm{PPh}_{3}$ can improve the selectivity, as the later ligand would reduce isomerization, while the former would guarantee the hydroformylation [15]. Thus, we performed the hydroformylation of 3-carene in the simultaneous presence of both ligands (Table 1, entry 11) but the system behaved quite similarly to the one with $\mathrm{PPh}_{3}$ only (entry 8).

In most of the runs with $\mathrm{P}\left(\mathrm{O}-{ }^{-}-{ }^{\mathrm{t}} \mathrm{BuPh}\right)_{3}$, the trans isomer of 4 (compound 4a) is formed predominantly, with only trace amounts of cis isomer $\mathbf{4 b}$ being detected by GC. However, in the absence of the P-ligand, appreciable amounts of $\mathbf{4 b}$ were formed $(\mathbf{4 a} / \mathbf{4 b}=9 / 1)$, which allowed us to perform its complete NMR characterization. Aldehyde $\mathbf{5}$ also has a trans configuration, and no cis isomer has been detected by NMR in the isolated mixtures (see Section 3.2). Thus, the hydroformylation of both carenes with the $\mathrm{Rh} / \mathrm{P}\left(\mathrm{O}-\mathrm{o}-{ }^{\mathrm{t}} \mathrm{BuPh}\right)_{3}$ catalyst occurs with almost $100 \%$ diastereoselectivity. The preferential formation of trans isomers is not unexpected, as it requires the catalyst coordination to the less sterically hindered face of the olefins, anti to the isopropylidene bridge. The syn addition of a rhodium(I) hydride to the coordinated olefin results in thermodynamically more stable (less hindered) rhodium alkyl intermediates, and then originates thermodynamically more stable trans aldehydes $\mathbf{4 a}$ or $\mathbf{5 a}$.

It is noteworthy that 3-carene reacts under hydroformylation conditions at lower rates than 2-carene, although the double bond of the latter seems to be sterically more encumbered. A possible explanation is that 2-carene has a higher tension in the bond angles of the six-member ring imposed by the rigidity of the double bond next to the cyclopropane ring, which would put 1 on a higher energetic level than 2 . The extra driving force for the reactivity of $\mathbf{1}$ would be the release at this tension either by the double bond isomerization or by its hydroformylation. The higher reactivity of 2-carene has already been described [22], and explained by the particular stability of the 3-carene molecule in its preferred boat conformation. In this conformation, the cyclopropane resides directly over the $\pi$-orbitals of the double bond, which implies stabilization for the molecule through $\pi$-overlap of the double bond with the cyclopropane electronic system. Thus, the double bond will have less electronic density available to coordinate to the metal center. In addition, such considerations can also explain the surprisingly high stereoselectivity of the hydroformylation of 3-carene, which is even higher than that of 2-carene: the face syn to the isopropylidene bridge is blocked due to the interaction of the double bond with the cyclopropane ring.

Table 2 demonstrates the effect of the $\mathrm{P}\left(\mathrm{O}-\mathrm{O}^{\mathrm{t}}{ }^{\mathrm{t}} \mathrm{BuPh}\right)_{3} / \mathrm{Rh}$ atomic ratio on the hydroformylation of $\mathbf{1}$ and $\mathbf{2}$. We intended to determine the optimal ratio $\mathrm{P} / \mathrm{Rh}$ as it was reported that a value as high as 50 may be beneficial [23]. For the hydroformylation of 2-carene, the promoting effect of the bulky phosphite may be noticed from the P/Rh ratio of 10 (entry 12). With the increase in the $\mathrm{P} / \mathrm{Rh}$ to 20 (entry 4), this effect is enhanced as the amount of isomeric 3-carene after $24 \mathrm{~h}$ is reduced and the selectivity for 4 increases. A further increase in the P/Rh ratio to 30 (entry 13) does not lead to any significant improvement neither in activity nor in selectivity, which demonstrates that $\mathrm{P} / \mathrm{Rh}=20$ under 
these reaction conditions is enough to keep most of the metal centers coordinated to one $\mathrm{P}\left(\mathrm{O}-\mathrm{o}-{ }^{\mathrm{t}} \mathrm{BuPh}\right)_{3}$. A similar behavior was observed in the hydroformylation of 3-carene. As mentioned above, in the hydroformylation of 3-carene, significant amounts of aldehyde $\mathbf{4}$ are always formed because the more reactive 2 -carene is consumed faster, driving the equilibrium between 3-carene and 2-carene towards the latter.

We have also studied the effects of the total and partial pressures of both $\mathrm{CO}$ and $\mathrm{H}_{2}$ on the activity and selectivity of the catalyst in the hydroformylation of 2-carene (Table 3). Usually, for the hydroformylation of $\alpha$-olefins catalyzed by rhodium/triarylphosphines systems under "standard oxo conditions" (10-50 atm, $\left.70-120^{\circ} \mathrm{C}\right)$, the reaction is zero order in hydrogen and negative order in $\mathrm{CO}$ concentration, while at low pressures and low temperatures a positive order in the hydrogen pressure can be observed [24]. For the Rh/P(O$o$ - $\left.{ }^{\mathrm{t}} \mathrm{BuPh}\right)_{3}$ system this dependence is strongly related with the nature of the substrate. For 1-octene the rate is first order in $\mathrm{H}_{2}$, inverse order in $\mathrm{CO}$, and zero order in the substrate concentration, what strongly suggests the hydrogenolysis as the rate-determining step. On the other hand, for the more encumbered cyclohexene the rate is slightly positive in hydrogen $(0.2)$, negative in $\mathrm{CO}(-0.65)$, and first order in cyclohexene, which suggests the olefin coordination as the rate-determining step. [25]

Under the conditions we used, the increase in the $\mathrm{CO}$ pressure by a factor of two decreases the conversion by a factor of 0.9 (Table 3, entries 16 versus 18) and the increase in the $\mathrm{H}_{2}$ pressure by a factor of two increases the conversion by a factor of 1.1 (entries 17 versus 18) in $24 \mathrm{~h}$. Although the initial rates cannot be extrapolated from these preliminary data, they suggest a behavior for 2-carene hydroformylation similar to the one observed for cyclohexene [25]. The increase in the total pressure of the equimolar gas mixture from 40 to 80 atm leads to no significant changes in the conversion or in the selectivity (Table 3, entries 16 versus 5). This might reflect a net nullified result of the opposite kinetic effects of the $\mathrm{CO}$ and hydrogen concentrations at $80{ }^{\circ} \mathrm{C}$. Thus, the hydroformylation of 2carene may be carried out under relatively mild reaction conditions $\left(80{ }^{\circ} \mathrm{C}\right.$ and $40 \mathrm{~atm}$ of $\left.\mathrm{CO} / \mathrm{H}_{2}=1\right)$.

\subsection{Hydroformylation of 2-carene and 3-carene: Stereochemistry of the products}

The stereochemistry of the products $\mathbf{4 a}$ and $\mathbf{4 b}$ was clarified by NOESY experiments. In both isomers, two methylene protons H-5 appear as two multiplets in two different regions of the spectra (Fig. 1). The proximity of the bulky isopropylidene bridge and the steric hindrance lead to a higher electron density on the hydrogen in a cis position to the isopropylidene group resulting in a shielding effect. Thus, cis $\mathrm{H}-5$ in both isomers appear at 0.61-0.67 ppm, while trans $\mathrm{H}-5$ at $1.71-1.77 \mathrm{ppm}$ in 4a and 1.94-2.03 ppm in 4b. It is remarkable that cis $\mathrm{H}-5$ gave a NOE with proton $\mathrm{H}-11$ of the formyl group in $\mathbf{4 b}$ but not in $\mathbf{4 a}$. This clearly indicates a cis configuration for $\mathbf{4 b}$ (the formyl and isopropylidene groups are at the same side of the cyclohexane ring).
In trans isomer $\mathbf{4 a}$, the proximity of the formyl group and trans proton $\mathrm{H}-5$, both at the same side of the cyclohexane ring, increases the electron density on this proton, so its signal expectedly appears more shielded compared to that of the cis isomer (1.71-1.77 ppm in 4a versus $1.94-2.03 \mathrm{ppm}$ in $\mathbf{4 b}$ ). The following additional evidence confirms this assignment. In trans isomer $\mathbf{4 a}$, both methyl groups of the isopropylidene fragment exhibit the same ${ }^{13} \mathrm{C}$ and ${ }^{1} \mathrm{H}$ signals, as the formyl group is at the other side of the cyclohexane ring. On the other hand, in cis isomer $\mathbf{4 b}$, there is a considerable difference in the electronic environments of the methyl groups C-8 and C-9, therefore the one which is closer to the formyl group (C-8) appears more shielded (21.01 and 0.86 ppm versus 21.72 and $1.06 \mathrm{ppm})$.

The stereochemistry of product $\mathbf{5 a}$ was also elucidated by NOESY experiments. Similarly to protons H-5 in $\mathbf{4 a}$ and $\mathbf{4 b}$, two methylene protons $\mathrm{H}-2$ in $\mathbf{5 a}$ appear as two multiplets in two different regions of the spectra (Fig. 2). Cis $\mathrm{H}-2$ shows the signal at $0.70-0.77$ ppm because of the proximity of the bulky isopropylidene bridge, while trans $\mathrm{H}-2$ appears less shielded at 1.94-2.03 ppm. Trans proton $\mathrm{H}-2$ gives a strong correlation signal with $\mathrm{H}-11$ of the formyl group showing their spatial proximity. Moreover, in 5a, as in trans isomer $\mathbf{4 a}$, both methyl groups of the isopropylidene fragment, C-8 and C-9, show the same signals in the ${ }^{13} \mathrm{C}$ and ${ }^{1} \mathrm{H}$ spectra. Based on these observations, we have attributed a trans configuration shown in Fig. 2 for the isomer $\mathbf{5 a}$.

\subsection{Hydroformylation of $\alpha$-pinene}

We employed the rhodium $/ \mathrm{P}\left(\mathrm{O}-\mathrm{o}^{\mathrm{t}}{ }^{\mathrm{BuPh}}\right)_{3}$ system for the hydroformylation of another sterically demanding olefin, $\alpha$ pinene (3), which contains an endocyclic trisubstituted double bond and a isopropylidene bridge similar to the carenes. The results are presented in Table 4. $\alpha$-Pinene also has an endocyclic trisubstituted double bond and isopropylidene bridge, which generate a great steric hindrance. Using the bulky $\mathrm{P}\left(\mathrm{O}-o-{ }^{\mathrm{t}} \mathrm{BuPh}\right)_{3}$ ligand, $\alpha$-pinene was completely converted under relatively mild conditions $\left(100{ }^{\circ} \mathrm{C}\right.$ and $40-80 \mathrm{~atm}$ of $\mathrm{CO} / \mathrm{H}_{2}=1$ ) in a $24-\mathrm{h}$ reaction giving aldehyde $\mathbf{6}$ as a main product. This aldehyde might be formed as a pair of diasteroisomers, $\mathbf{6 a}$ and $\mathbf{6 b}$, which differ from each other on the relative position of the isopropylidene bridge and the formyl group. However, NMR studies revealed that, as in the case of

Table 4

Rhodium catalyzed hydroformylation of $\alpha$-pinene (3) promoted by $\mathrm{P}\left(\mathrm{O}-\boldsymbol{o}^{\mathrm{t}}{ }^{\mathrm{B}} \mathrm{Bu}-\right.$ $\mathrm{Ph})_{3}{ }^{\mathrm{a}}$

\begin{tabular}{llllrlr}
\hline Entry & {$[\mathrm{P}] /[\mathrm{Rh}]$} & \multicolumn{3}{c}{ Conversion $(\%)$} & \multicolumn{4}{c}{ Product distribution $(\%)$} \\
\cline { 3 - 7 } & & & $\mathbf{6 a}$ & $\mathbf{1 0 a}$ & $\mathbf{1 0 b}$ & Others \\
\hline 19 & 10 & 94 & 57 & 15 & 19 & 9 \\
20 & 20 & 93 & 63 & 9 & 18 & 10 \\
$21^{\mathrm{b}}$ & 20 & 94 & 49 & 22 & 16 & 13 \\
\hline
\end{tabular}

${ }^{\mathrm{a}}$ Reaction conditions: substrate: $2.5 \mathrm{mmol} ; \quad[\mathrm{Rh}(\operatorname{cod})(\mathrm{OMe})]_{2}: 3.1 \times$ $10^{-3} \mathrm{mmol}$; $\mathrm{P}\left(\mathrm{O}-o^{-}{ }^{\mathrm{t}} \mathrm{BuPh}\right)_{3}: 1.2 \times 10^{-1} \mathrm{mmol}$; benzene: $5 \mathrm{~mL} ; 80 \mathrm{~atm}(\mathrm{CO} /$ $\left.\mathrm{H}_{2}=1\right) ; 100{ }^{\circ} \mathrm{C} ; 24 \mathrm{~h}$.

b $40 \mathrm{~atm}\left(\mathrm{CO} / \mathrm{H}_{2}=1\right)$. 
aldehydes $\mathbf{4}$ and 5, only one isomer, $\mathbf{6 a}$ is formed exclusively, not even a trace of the other possible isomer $\mathbf{6 b}$ has been detected neither by GC nor by NMR in the isolated product.

We have found that in the NOESY spectrum of $\mathbf{6 a}$, hydrogen $\mathrm{H}-3$ (attached to the carbon atom bound to the formyl group) shows a strong correlation signal with methyl protons H-8 showing that they are at the same side of the cyclohexane ring. This clearly indicates a trans configuration for aldehyde $\mathbf{6 a}$ depictured in Fig. 2. The predominant formation of the trans isomer is also not unexpected as it requires the catalyst coordination to the less sterically hindered face of $\alpha$-pinene, anti to the isopropylidene bridge. As with carenes, this leads to less hindered rhodium alkyl and acyl intermediates, and then to thermodynamically more stable trans aldehyde $\mathbf{6 a}$.

Similar to what has been observed for carenes, the hydroformylation of $\alpha$-pinene is complicated by its isomerization giving $\beta$-pinene 9 (Scheme 3). Terminal olefin 9 is readily hydroformylated under the reaction conditions to form a pair of diastereoisomers 10a (trans) and 10b (cis) in comparable amounts. The balance between the competitive reactions during the hydroformylation of $\alpha$-pinene seems to be affected by the reaction conditions such as the $\mathrm{P} / \mathrm{Rh}$ ratio and pressure (cf. Table 4, entries 19-21). The low diastereoselectivity of the hydroformylation of $\beta$-pinene reflects the fact that the discrimination between the two diastereotopic faces in $\beta$ pinene is much more difficult than for $\alpha$-pinene and carenes.

\section{Conclusions}

In this work the hydroformylation of monoterpenes containing a sterically encumbered trisubstituted endocyclic double bond, 2-carene, 3-carene, and $\alpha$-pinene, has been systematically studied. In unmodified systems, the rhodium catalyst promotes an intense isomerization of both carenes whose hydroformylation occurs rather slowly and results in a complex mixture of aldehydes and alcohols. The addition of $\mathrm{PPh}_{3}$, diphosphines or $\mathrm{P}(\mathrm{OPh})_{3}$ effectively prevents the isomerization only at a $\mathrm{P} / \mathrm{Rh}$ ratio of at least 20 . However, such conditions favor the formation of bis(ligand) and tris(ligand) rhodium species, which have little or no activity in the hydroformylation of these substrates. On the other hand, the use of $\mathrm{P}\left(\mathrm{O}-\mathrm{o}^{\mathrm{t}} \mathrm{BuPh}\right)_{3}$ allowed a reduction in the isomerization and a significant increase in the hydroformylation rate. Due to the large cone angle of this ligand, catalytically active monoligand rhodium species predominate in the reaction solutions even at high $\mathrm{P} / \mathrm{Rh}$ ratios. Moreover, its electronic properties favor the olefin coordination and $\mathrm{CO}$ dissociation. All three substrates have been efficiently hydroformylated under relatively mild reaction conditions $\left(80-100{ }^{\circ} \mathrm{C}, 40\right.$ $80 \mathrm{~atm}$ ) with high chemoselectivity for main aldehydes and almost $100 \%$ stereoselectivity for their trans isomers formed through the coordination of monoterpenes via their less hindered face to the rhodium center.

\section{Acknowledgments}

Financial support from CNPq, FAPEMIG, and DGI (CTQ2005-09187-C02-01), as well as scholarships from CNPq, CAPES, FAPEMIG and Project CYTED V9 are gratefully acknowledged.

\section{References}

[1] A.J. Chalk, in: P.N. Rylander, H. Greenfield, R.L. Augustine (Eds.), Catalysis of Organic Reactions, Vol. 22, Marcel Dekker, New York, 1988 pp. 43-63.

[2] E.V. Gusevskaya, Quím. Nova 26 (2003) 242.

[3] K.A.D. Swift, Top. Catal. 27 (2004) 143.

[4] H.J.V. Barros, M.L. Ospina, E. Arguello, W.R. Rocha, E.V. Gusevskaya, E.N. Dos Santos, J. Organomet. Chem. 671 (2003) 150.

[5] H.J.V. Barros, B.E. Hanson, E.V. Gusevskaya, E.N. Dos Santos, Appl. Catal., A-General 278 (2004) 57.

[6] L.L. Da Rocha, A.D.O. Dias, E.N. Dos Santos, R. Augusti, E. Gusevskaya, J. Mol. Catal. A: Chem. 132 (1998) 213.

[7] A.C. Da Silva, K.C.B. De Oliveira, E.V. Gusevskaya, E.N. Dos Santos, J. Mol. Catal. A: Chem. 179 (2002) 133.

[8] C.M. Foca, E.N. Dos Santos, E.V. Gusevskaya, J. Mol. Catal. A: Chem. 185 (2002) 17.

[9] C.M. Foca, H.J.V. Barros, E.N. Dos Santos, E.V. Gusevskaya, J. Carles Bayon, New J. Chem. 27 (2003) 533.

[10] E.V. Gusevskaya, E.N. Dos Santos, R. Augusti, A.D.O. Dias, C.M. Foca, J. Mol. Catal. A: Chem. 152 (2000) 15.

[11] H. Siegel, W. Himmele, Tetrahedron Lett. 12 (1976) 907.

[12] H. Siegel, W. Himmele, Angew. Chem. Int. Ed. 19 (1980) 178.

[13] I. Cipres, P. Kalck, D.C. Park, F. Serein-Spirau, J. Mol. Catal. 66 (1991) 399.

[14] E.N. Dos Santos, C.U. Pittman Jr., H. Toghiani, J. Mol. Catal. 83 (1993) 51.

[15] V.M. Tormyshev, G.A. Skripko, V.D. Shteingarts, II Europacat, S9, 1995, p. 36.

[16] S. Sirol, P. Kalck, New J. Chem. 21 (1997) 1129.

[17] R. Usón, L.A. Oro, C. J, Inorg. Synth. 23 (1985) 126.

[18] P.W.N.M. Van Leeuwen, C.F. Roobeek, J. Organomet. Chem. 258 (1983) 342.

[19] F. Azzaroni, P. Biscarini, S. Bordoni, G. Longoni, E. Venturini, J. Organomet. Chem. 508 (1996) 59.

[20] Z. Freixa, M.M. Pereira, J.C. Bayon, A.M.S. Silva, A.M. Salvador, J.A. Beja, M.R. Paixao, Tetrahedron: Asymmetry 12 (2001) 1083.

[21] P.C.J. Kamer, J.N.H. Reek, P.W.N.M. Van Leeuwen, in: P.W.N.M. van Leeuwen, C. Claver (Eds.), Rhodium Catalyzed Hydroformylation, Kluwer, Dordrecht, 2000, pp. 35-59.

[22] W.E. Erman (Ed.), Chemistry of the Monoterpenes. An Encyclopedic Handbook, Marcel Dekker, New York, 1985, p. 870.

[23] A. van Rooy, E.N. Orij, P.C.J. Kamer, F. van Den Aardweg, P.W.N.M. van Leeuwen, J. Chem. Soc., Chem. Commun. (1991) 1096.

[24] P.W.N.M. van Leeuwen, C.P. Casey, G.T. Whiteker, in: P.W.N.M. van Leeuwen, C. Claver (Eds.), Rhodium Catalysed Hydroformylation, Kluwer, Dordrecht, 2000, pp. 63-96.

[25] A. Van Rooy, E.N. Orij, P.C.J. Kamer, P.W.N.M. Van Leeuwen, Organometallics 14 (1995) 34. 